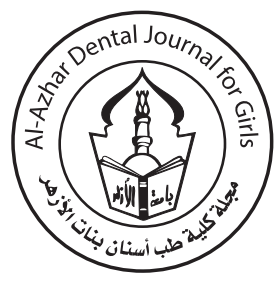

\title{
Solubility and Sealing Ability of Recently Introduced Biocearmic Root-End Filling Materials
}

\author{
Amira A. Moustafa ${ }^{1 *}$, Inas T. Motawea ${ }^{2}$, Rania E. Bayoumi $^{3}$
}

Codex : 68/20.10

azhardentj@azhar.edu.eg

http://adjg.journals.ekb.eg

DOI: $10.21608 /$ adjg.2020.14153.1177

Restorative Dentistry

(Removable Prosthodontics, Fixed

Prosthodontics, Endodontics, Dental Biomaterials, Operative Dentistry)

\section{KEYWORDS}

Retrograde filling, MTA,

BIO MTA, Bioceramic.

\begin{abstract}
Purpose: the current study was conducted for evaluation of solubility and sealing ability of two recently introduced biocearmic root end filling materials (Bio MTA and Total Fill) in comparison to the gold standard Mineral Trioxide Aggregate (MTA).Materials and Methods: Regarding solubility test a total of 15 disc specimens were fabricated from the three tested materials. The discs were then divided randomly into three equal groups $(n=5)$ according to tested root end filling materials (Pro root MTA, Bio MTA, and Total Fill biocearmic). The solubility test was done according to ISO no 6786. The amount of residue weight from each specimen was estimated and expressed as a percent of solubility. While for sealing ability testing, a total number of 15 freshly extracted human mandibular premolars with straight roots, single canal, and fully formed root apices were selected, and the crown was removed and canal was prepared and obturated, then the apical $3 \mathrm{~mm}$ of each root was removed. The root-end cavity with $3 \mathrm{~mm}$ in depth and $1.5 \mathrm{~mm}$ in width was done using diamond ultrasonic tips. The tested materials were mixed and placed inside the cavities. The specimens were sectioned by isomet for further environmental scanning electron microscopic investigation of sealing ability. Results: In both tests a significant difference was found between the control group (MTA group) and two tested groups (Total Fill group, Bio MTA group) where $(\mathrm{p}<0.001)$.Moreover, the Bio MTA group and Total Fill group showed a lower solubility $\%$ and higher sealing ability in comparison to Pro root MTA group and this was explained in term of negative correlation between the solubility \%and sealing ability. Conclusions: Total Fill and Bio MTA exhibits less solubility \% and better sealing ability compared to the Pro root MTA. Based on improved sealing ability of both Total Fill and Bio MTA material, they could be considered as a good choice for the replacement of conventional MTA as root end filling materials
\end{abstract}

- Paper extracted from Master thesis titled "Solubility and Sealing Ability of Recently Introduced Biocearmic Root-End Filling Materials"

1. Dentist at Egyptian Ministry of Health.

2. Professor of Dental Biomaterials, Vice Dean for Research Studies and Research, Faculty of Dental Medicine for Girls, AlAzhar University, Cairo, Egypt

3. Assistant Professor of Dental Biomaterials, Faculty of Dental Medicine for Girls, Al Azhar University, Cairo, Egypt

* Corresponding author email: balah_amira@yahoo.com 


\section{INTRODUCTION}

Endodontic surgery is an alternative to dental extraction to save the tooth when conventional re-treatment had failed or impossible to be made. One of the main goals of endodontic surgery is to improve the apical seal and this could be done by placing biocompatible root end filling material in well prepared root end cavity. The root end filling material acting as a "physical seal" to prevent the passage of microorganisms or their products from the root canal system into the adjacent periradicular tissues ${ }^{(1,2)}$.

One of the important criteria of this material is the prevention of bacteria leakage from the root canal to the periapical tissue. Moreover, it should be biocompatible, antibacterial, adaptable to the dentinal walls, have fast initial setting time to decrease its solubility, radiopaque to allow detection of filing quality, and finally bioactive able to induce regeneration of the periodontal ligament complex, specifically cementogenesis over the root-end filling itself ${ }^{(3-5)}$.

A variety of materials have been used as rootend filling materials, like amalgam, reinforced zinc oxide eugenol-based cement (IRM) which considered as one of the most popular root end filling material. But many studies were recorded high leakage with both of them. Moreover, glass ionomer cement (GIC) with some modifications was used for a period of time but with questionable sealing ability and low solubility resistance ${ }^{(7,8)}$.

Mineral Trioxide Aggregate (MTA) has demonstrated the excellent physicochemical properties, including adequate sealing ability and adaptation to the dentinal walls, high radiopacity and relatively low solubility. Also it has excellent tissue response. Moreover, MTA was a biocompatible material that stimulated periradicular tissue repair at the rootend. MTA still the gold standard material in most of cases ${ }^{(9,10)}$.
Despite the good physical and biological properties of MTA, but it has a drawback of long setting time of about $45 \mathrm{~min}$. to 2 hours, so the material must be protected before they fully set. To overcome all this drawbacks, other new materials was developed ${ }^{(11,12)}$.

Bio MTA was introduced to overcome some of the drawbacks of MTA such as handling properties and long setting time. Bio MTA has a faster setting time with good handling characteristics and biological properties. Moreover, Calcium silicate based restorative cement was formulated using different calcium compounds such as calcium hydroxide, calcium oxide, calcium phosphate, calcium sulfate, calcium silicate, and calcium carbonate. The mixed cement comprises water-soluble calcium and phosphate which immediately forms hydroxyapatite during and after setting that provide more sealing ability for the apical part ${ }^{(13-15)}$.

Furthermore, the handling and placement of the material is still a major problem. The poor handling of the materials will eventually lead to improper placement that will lead to defective sealing ability. For this reason a Total Fill biocearmic root repair material which is calcium silicate based cement was developed with excellent handling properties as it is supplied in premixed packages (putty) that do not require preparation before use. It is mainly composed of calcium silicate, monobasic calcium phosphate, calcium hydroxide, and zirconium oxide. It has antibacterial and antifungal activities. It is claimed that the material is biocompatible with human periodontal tissues ${ }^{(16,17)}$.

The accuracy of apical seal achieved by retrograde filling materials has been evaluated by various means like the penetration degree of dye, radioisotope penetration, bacterial penetration, and fluid filtration methods ${ }^{(18,19)}$. The sealing ability of the material is one of the most desirable criteria for the retrograde material. Therefore, to assess the sealing ability at the filling material tooth interface the scanning electron microscope is the most valuable tool for such test ${ }^{(20)}$ 
It was postulated that sealing ability was more related to solubility of the root end filling material. Therefore, the present study was directed to evaluate the solubility and sealing ability of different biocearmic root-end filling materials (Mineral Trioxide Aggregate (MTA), Bio MTA and Totalfill).

\section{MATERIALS AND METHOD}

Pro root MTA (DENTSPLY Tulsa U.S.A. (12002493), BioMTA retrograde(Bio MTA.CO. Seoul, Korea (1608D14) and Total Fill bio ceramic root repair material putty (BRASSELER USA. (3952f)) were used in the current study.

\section{Solubility test}

Solubility test was conducted in accordance with the International Standards Organization (ISO) 6876 Method and with the American Dental Association (ADA) specification \# $30^{(12,21)}$.

\section{Specimens' Preparation}

A total of 5 disc specimens of each root end filling material ( Pro root MTA, Bio MTA, and Total Fill biocearmic) were prepared using a split teflon mold of circular space $10 \mathrm{~mm}$ in diameter and $2 \mathrm{~mm}$ in thickness. A convenient length of dental floss (Oral B dental floss (234587).)was weighed (M1) using an electric balance having sensitivity of $0.0001 \mathrm{~g}$. Pro root MTA, Bio MTA root and Total Fill root end filling materials were manipulated according to manufacturer instructions with 3:1 powder: liquid ratio for both Pro root MTA, Bio MTA. The dental floss was inserted in the three tested materials before setting. Specimens were left to set in a humidor and placed inside an incubator cabinet maintained at $37^{\circ} \mathrm{C}$ for 24 hours. For each specimen a clean dry bottle was weighed using the electric balance (A GP 600 P Sartorius analytical balance, DWS, Inc.). The bottle was dried at $150^{\circ} \mathrm{C}$ for at least 2 hours in an oven, then cooled for 1 hour at room temperature in a desiccator containing silica gel .This weight is recorded as dry bottle weight (M2) . Then the specimen was placed in the corresponding bottle and was weighed (M3).Where:M1, indicate the weight of dental floss, M2, indicate the weight of dry bottle and $\mathbf{M 3}$, and indicate the weight of bottle containing the specimen.

The prepared disc was suspended by the dental floss so that it does not touch the sides of the bottle and submerged by pouring $50 \mathrm{ml}$ of distilled water into the bottle. The bottle was closed tightly and stored in an incubator maintained at $37^{\circ} \mathrm{C}$ for a period of 24 hours. An amount $50 \mathrm{ml}$ of distilled water was poured into a separated blank bottle (with no specimen) and placed in the same incubator at $37^{\circ} \mathrm{C}$ for a period of 24 hours. After 24 hours of immersion, the specimen was removed and the water was evaporated in an oven at a temperature slightly below boiling point $\left(90^{\circ} \mathrm{C}\right)$. After the evaporation of water (from both the empty bottle and the bottle containing the specimen), the bottles were dried for 24 hours in an oven at $110^{\circ} \mathrm{C}$, then cooled to room temperature, then weighed (M4). The increase in weight of the blank bottle due to presence of distilled water residual was determined as (M5). The amount of water leachable content from the specimen was expressed as percentage of solubility by the following equation according to ISO 6876 standard.

$$
\text { Solubility } \%=\frac{\mathrm{m} 4-(\mathrm{m} 5+\mathrm{m} 2)}{\mathrm{m} 3-(\mathrm{m} 2+\mathrm{m} 1)} \times 100
$$

Where: M4, indicate the weight of dried bottle with the specimen residue and M5, indicate the weight of blank bottle containing water residue subtracted from the weight of the blank bottle.

\section{Sealing Ability test}

\section{Teeth Selection}

The teeth used in this study were obtained from patients of private clinics who have already signed a consent form on their approval of using their teeth as specimens and were extracted for pulpal or periodontal reasons. This study was approved from the Ethical Committee of Faculty of Dental Medicine for Girls, Al-Azhar University. 
A total number of 15 freshly extracted human mandibular premolars with straight roots, single canal, and fully formed root apices were selected for the current study. The selected teeth were radiographically examined to exclude any roots that had abnormalities such as calcifications, fractures and root resorptions (external or internal). The teeth were cleaned from any hard deposits using ultrasonic scaler (Satalec, France )and immersed into $5.25 \%$ sodium hypochlorite(Egyptian Company for households bleach, Egypt) solution for 30 minutes to remove any soft tissue as it has high affinity to remove the soft tissue and remaining PDL tissue from the external root surface due to its dissolving power. Then the teeth were stored in normal saline (El Fath for drug and cosmetic industry) solution $0.9 \%$ at room temperature till time of use due to its isotonic nature and has no action on the surface integrity of tooth structure.

\section{Specimens' Preparation}

The teeth were transversely sectioned at the cemento-enamel junction to allow specimens length standardization of $15 \mathrm{~mm}$ by using a diamond disc (Komet, Germany ,8105466) mounted in lowspeed handpiece under water cooling. Entrance to canal was made in 15 teeth, then each canal was prepared using ProTaper Next rotary files system (DENTSPLY MAILFER 134526) according to manufacturer instructions with the following sequence $\mathrm{X} 1$, $\mathrm{X} 2$ and end to $\mathrm{X} 3$ in a crown down motion that allow maximum reduction of root canal microorganisms and maximum penetration of irrigant solution. Irrigation was performed using $2.5 \%$ sodium hypochlorite by using a side vented 27 -gauge needle, the needle was positioned $2 \mathrm{~mm}$ shorter than the working length during irrigation in order to ensure adequate irrigant flow especially at the apex resulting in more debris removal and proper fluid exchange and displacement.

Furthermore, root canal obturation was done using gutta- percha cemented with resin sealer. Excess gutta-percha cones was removed from the orifice with hot instrument then the specimens were stored at $37^{\circ} \mathrm{C}$ and $100 \%$ humidity for 24 hours to allow complete setting of obturation materials. Then the apical $3 \mathrm{~mm}$ of each root was removed with a diamond disc mounted in low-speed handpiece, under water spray, at 90 degrees to the long axis of the tooth. Then the root-end cavity preparations (class1 cavity with $3 \mathrm{~mm}$ in depth and $1.5 \mathrm{~mm}$ in width) ${ }^{(3)}$ was done using diamond ultrasonic tips ( Satelec, France) The root specimens were kept in a moist gauze to simulate the clinical condition.

The root-end filling materials (Pro root MTA, Bio MTA, Total Fill), were manipulated according to the manufacturer's instructions in order to have a homogenous mix. Pro root MTA is supplied as a pack of $0.5 \mathrm{~g}$ and Bio MTA is $0.3 \mathrm{~g}$, with a premeasured unit dose of water for convenience mixing. Upon mixing, the Pro root MTA and Bio MTA material reached the working consistency rapidly and were ready to be placed into the prepared cavity with a special carriers. However, the total fill was already supplied as a ready made putty form so it didn't need any kind of mixing. It was placed directly inside the prepared cavity with a carver and packed with a plugger.

Moreover, radiographs were made for all specimens to evaluate the quality of the root-end fillings. More packing was done to obtain excellent adaptation radiographically (Vatech, HD, Korea, LTD.) Furthermore, the specimens were wrapped with moist gauze at $37^{\circ} \mathrm{C}$ and $100 \%$ humidity till complete setting.

\section{Environmental Scanning Electron Microscope (ESEM)}

The specimens were longitudinally sectioned by using water cooled low speed diamond disc isomet (iBuehler Ltd, Germany) device at $2550 \mathrm{rpm}$ speed .The specimens were examined using ESEM which was maintained at approximately $15 \mathrm{Kv}$ and 10-6 
Torr under high vacuum condition. Specimen imaging was done by secondary electrons using a secondary electron detector. The surface of each tested specimen was viewed and photographically recorded with a charged couple device (CCD) at low magnification (200x). The magnification was then elevated up to 2000x for each specimen at the material-tooth interface; the gap distance in microns was recorded at five points. All the specimens were photographed at five points at 2000x.

\section{Statistical Analysis}

In each test, the calculation of mean value and standard deviation (SD) value were done for all groups. The collected data showed normal distribution after exploration of normality by using Kolmogorov-Smirnov and Shapiro-Wilk tests. Moreover, to compare between more than two groups in non-related samples one-way ANOVA followed by Tukey post hoc test was used. The level of significance was set at $\mathrm{P} \leq 0.05$. Statistical analysis was performed with IBM ${ }^{\circledR}$ SPSS ${ }^{\circledR}$ Statistics Version 20 for Windows.

\section{RESULTS}

\section{Solubility \%:}

The mean and standard deviation values for the solubility $\%$ of all tested groups are shown in table (1) and graphically represented in figure (1). The results reveled that, there was a statistically significant difference between the control group (MTA group) and the other tested groups. The Pro root MTA group recorded the statistically highest solubility \% (3.17 \pm 0.99$)$. Meanwhile, the Bio MTA group and Total Fill group showed a lower solubility \% in comparison to Pro root MTA group (1.04 \pm 0.50 and $1.02 \pm 0.44$ respectively).

However, no statistically significant difference was recorded between Bio MTA group and Total Fill group $(p>0.05)$.
Table (1): The mean, standard deviation (SD) values of solubility\% in tested groups.

\begin{tabular}{|c|c|}
\hline Group & Mean \pm SD \\
\hline MTA Group & $3.17^{\mathrm{a}} \pm 0.99$ \\
\hline Bio MTA Group & $1.04^{\mathrm{b}} \pm 0.50$ \\
\hline Total Fill & $1.02^{\mathrm{b}} \pm 0.44$ \\
\hline p-value & $<0.001^{*}$ \\
\hline
\end{tabular}

Means with Different letters indicates a statistically significant difference ${ }^{*}$; significant $(p<0.05)$

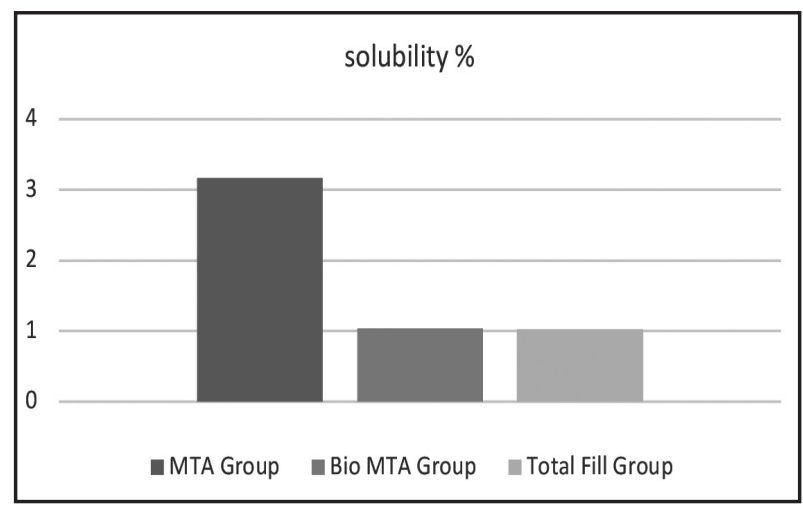

Figure (1) Bar chart representing solubility\% for tested groups

\section{Sealing ability:}

The mean and standard deviation values for the sealing ability of all tested groups are shown in table (2) and graphically represented in figure (2). The results reveled that, there was a statistically significant difference between the control group (Pro root MTA group) and the other tested groups. The Pro root MTA group recorded the statistically lowest sealing ability $(2.08 \pm 0.12)$. Meanwhile, the Bio MTA group and Total Fill group showed a higher sealing ability in comparison to Pro root MTA group $\left(8.13^{ \pm} 0.54\right.$ and $8.08^{ \pm} 0.50$ respectively). However, no statistically significant difference was recorded between BioMTA group and Total Fill group $(\mathrm{p}>0.05)$. 
Table (2): The mean, standard deviation (SD) values of sealing of different groups.

\begin{tabular}{|c|c|}
\hline Group & Mean \pm SD \\
\hline MTA Group & $2.08^{\mathrm{b}} \pm 0.12$ \\
\hline Bio MTA Group & $8.13^{\mathrm{a}} \pm 0.50$ \\
\hline Total Fill Group & $8.08^{\mathrm{a}} \pm 0.54$ \\
\hline p-value & $<0.001^{*}$ \\
\hline
\end{tabular}

Means with Different letters indicates a statistically significant difference *; significant $(p<0.05)$

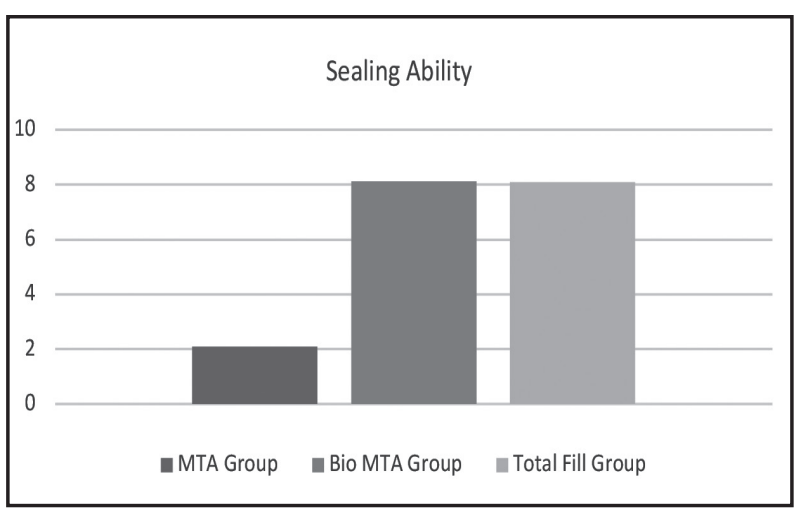

Figure (2) Bar chart representing sealing ability for different groups

\section{Environmental Scanning Electron Microscope (ESEM)}

Environmental Scanning Electron photomicro- graphs of the different tested materials and corresponding gap distance between the root end filling materials and dentin wall are presented in figures (3). Regarding the Pro root MTA, the photomicrograph showed the lowest adaptation between dentin wall and tested material which was indicated by a large gap distance which ranged (from 16.61 $\mu \mathrm{m}$ to $25.21 \mu \mathrm{m}$ ) as shown in figure (3 a). While the photomicrograph of Bio MTA material showed the highest adaptation with the dentin wall that was indicated by the lowest gap distance that ranged (from $6.27 \mu \mathrm{m}$ to $9.15 \mu \mathrm{m})$ as shown in figure (3b).

Moreover, the photomicrograph of Total Fill demonstrated more adaptation with the dentin wall than Pro root MTA as indicated by a small gap distance that ranged (from $1.49 \mu \mathrm{m}$ to $5.42 \mu \mathrm{m}$ ) as shown in figure (3c).

\section{Correlation between Solubility \% and Sealing ability}

Pearson correlation was used to find the correlation between two variables which are solubility\% and sealing ability are shown in table (3) and graphically represented in figure (4). There was a significant negative relationship between the solubility $\%$ and sealing ability value where $r=-0.703$, and $p$ value 0.003 , which stated that increasing in solubility percentage will be accompanied by decreasing in sealing ability.
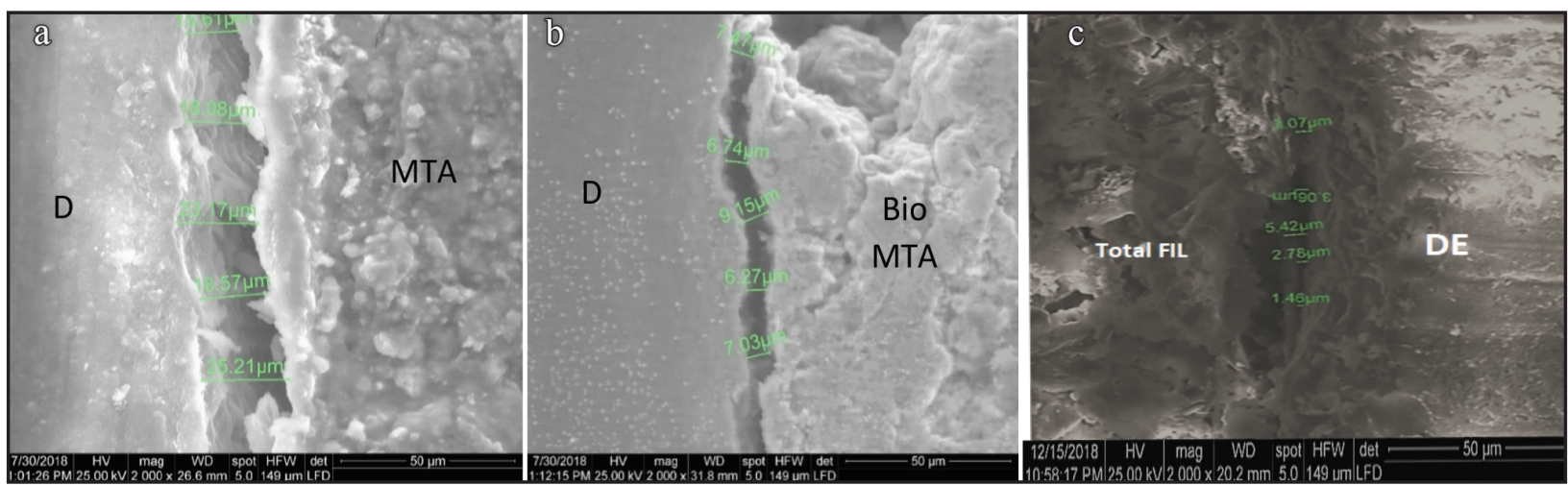

Figure (3) Scanning electron photomicrographs at magnification 2000x of a) Pro root MTA, b) Bio MTA, c) Total Fill 
Table (3): Correlation between Solubility \% and Sealing ability

\begin{tabular}{|c|c|}
\hline \multicolumn{2}{|c|}{ Pearson correlation } \\
\hline Correlation coefficient( R ) & -0.703 \\
\hline $\mathbf{r}^{2}$ & 0.495 \\
\hline P value & 0.003 \\
\hline
\end{tabular}

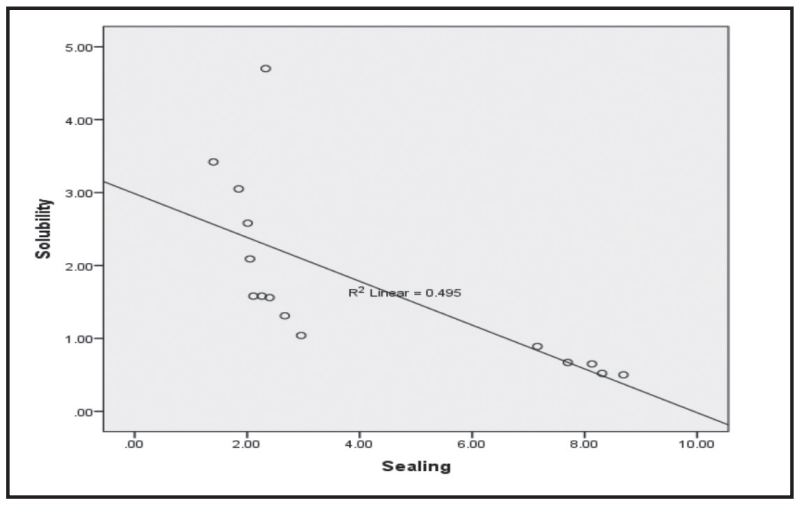

Figure (4) Scatter plot showing correlation between Solubility $\%$ and Sealing ability

\section{DISCUSSION}

Surgical intervention is required to preserve the teeth with post treatment failure when non-surgical retreatment fails to improve the condition. The spread of bacteria from the root canal to the surrounding tissues should be prevented when treating apical lesions. Root-end filling should be performed properly for the success of endodontic surgical procedures. ${ }^{(22)}$. The presence of smear layer which contains bacteria and necrotic tissues, limit the optimum penetration of disinfecting agents and medicaments into the dentinal tubules. It obstructs the extension of sealer tags into the dentinal tubules and thereby decreases adhesion by micro mechanical forces ${ }^{(23)}$.In this study, smear layer was removed using $15 \mathrm{ml}$ of $2.5 \%$ sodium hypochlorite for $3 \mathrm{~min}$ utes followed by $3 \mathrm{ml}$ of $17 \%$ EDTA solution for 1 minute then rinsed with saline to ensure complete removal of sodium hypochlorite and EDTA ${ }^{24}$.
In the current study all root canals were obturated by cold lateral compaction of gutta-percha with resin seal that provide easy and controlled placement of obturating material ${ }^{(25,26)}$. Apicectomy was done by removing the apical $3 \mathrm{~mm}$ of the root which contain maximum number of lateral canals that harbor bacteria which is the cause of reinfection of periapical tissues. This was done by using diamond disc at low speed contra-angle hand piece under continuous water spray and was done perpendicular to the long axis of the root with no bevel ${ }^{(27,28)}$. This procedure was done to allow more conservation of root structure, improved the crown root ratio, removes the majority of apical ramification and reduced the number of exposed open cut

Root end cavity was prepared by using diamond ultrasonic tip parallel to the long axis of the root and follows the anatomical outline of the pulp space (29). The cavity preparation was performed by using diamond ultrasonic tip for the conservation of root dentin and reducing the micro cracks that generated during procedures

MTA represents the standard benchmark to which other repair materials are compared to. It has many favorable properties that support its clinical use such as its biocompatibility, antimicrobial activity and promotes regeneration of the original tissue when placed in contact with dental pulp or periradicular tissue ${ }^{(30)}$. BioMTA was chosen in the current study, as it has high mechanical properties with excellent biocompatibility, as well as bioactive behavior. Moreover, the material has a very fast setting reaction (2.5 minutes) which made the single visit pulp therapy more acceptable ${ }^{(31,32)}$.

Total Fill biocearmic root repair material was selected in the present study which is a ready-made putty that allow easy handling and placement. It has a smaller particle size with excellent tissue reaction and biocompatibility ${ }^{(33)}$. It can be placed in incremental pattern which minimize the voids and enhance the sealing ability ${ }^{(30)}$. The material has 
indications similar to calcium silicate containing materials e.g. Bio MTA, it has better consistency, better handling, safety, and faster setting time which creates no need for a two-step obturation ${ }^{(31)}$.

Moreover, it is worthy to explain that, the chemical reaction that leads to the setting of MTA cement is called "hydration reaction" that happens when the fine hydrophilic powder particles are mixed with water. During the hydration process, calcium and hydroxyl ions originate from the dissolution of the calcium-silicate particles and form large amount of calcium hydroxide layer on the material surface ${ }^{(34-37)}$.

The results of the current study recorded that Pro root MTA showed the highest mean solubility $\%$ in comparison to Bio MTA and Total Fill. This could be attributed to the soluble components of MTA cement which are partially leached in water when set in an aqueous media as it is hydrophilic. This reaction is accompanied by high setting expansion which in turn provide space for more water uptake leading to leaching out of more soluble components of MTA cement ${ }^{(38)}$. Furthermore, MTA is composed of Portland cement and bisthmus oxide as a radiopacifier filler, the Portland cement particles is responsible for the setting reaction. However, bisthmus oxide does not contribute in the hydration reaction so it is easily leached out from the material. Moreover, adding Bismuth oxide prolongs the setting reaction which increased water uptake that lead to easily leaching out of large particle size of bisthmus oxide, that's finally lead to increased solubility ${ }^{(39-41)}$. These results are in agreement with other studies ${ }^{(34,37)}$, which showed that bisthmus oxide more leaching from Pro root MTA increased the solubility of the material in comparison with other materials that doesn't contain bisthmus oxide.

On the other hand, the Bio MTA and Totalfill materials have showed a decrease in the solubility $\%$ in comparison to Pro root MTA. This may be explained by both have fast initial setting time $(2.5$ minutes for Bio MTA, 30 minutes for total fill). This fast setting allow more resistance to wash out of its particles during the setting of the material. Moreover, these materials contain calcium zirconia complex with nanosized particles $\left(1 \times 10^{3} \mu \mathrm{m}\right.$ at its greatest size) which is more resistant for leaching out compared to easy release of free calcium ions which is present in MTA. Thus the solubility of zirconium containing materials (Bio MTA and Total fill) was less than the solubility of bisthmus oxide containing material (Pro root MTA) ${ }^{(1)}$.

This finding was in agreement with another study which concluded that zirconium oxide is more stable than bismuth oxide in the cement matrix ${ }^{(42,43)}$. However, these results were inconsistent with the results of a previous study which reported that the solubility of Bio MTA and Total Fill was higher than MTA. The high solubility is the result of hydrophilic nanosized particle which has high surface area that allows the more liquid molecule to come in contact and wet the particles. The discrepancy between the results may be attributed to variation in the methodology ${ }^{(44)}$.

In the current study, Bio MTA and Total Fill have higher sealing ability in comparison to Pro root MTA. This may be attributed to its large amount of hydroxyl, calcium, and phosphate ions, respectively, which readily alter and raise the $\mathrm{pH}$ of area lead to more hydroxyapatite crystal formation make them more able to close the gap which is responsible for increasing the sealing ability of the material ${ }^{(45)}$. Furthermore, the total fill materials form tag like structure in dentin that cause micromechanical interlocking and bonding to dentin which is not seen with pro root MTA. Good adaptation of the material is influenced by its flow and stickiness which is achieved by the putty consistency of Total Fill, thus, increasing the sealing ability ${ }^{(46,47)}$.

The results of the current study are in agreement with a previous study ${ }^{(48)}$ which concluded that 
the biocearmic root repair material showed better sealing ability when compared with other root repair materials. This may contradict a previous study ${ }^{(49)}$ which revealed no significant difference between PRO root MTA and biocearmic root repair material regarding the sealing ability. Moreover, another study ${ }^{(33)}$ showed that PRO root MTA has a significantly high sealing ability than biocearmic root repair.

Although, the MTA have high solubility but it still showed clinical acceptable sealing ability and this may be due to the formation of the large amount of calcium hydroxide crystals that initiate the deposition of cementum against MTA ${ }^{(34-37)}$.

Finally the results of the current study revealed that there is a negative correlation between the sealing ability of material and its solubility which indicted that increase in solubility will be accompanied by decreasing in sealing ability. This finding was accepted due to increase solubility of material may lead to degradation of bond between the root end filling material and root dentin that lead to gap and increase microleakage. Also increased the root end filling material solubility due to loss of surface integrity related to high leached out material particle. These results were in agreement with the previous studies which states that the loss of surface integrity of any material lead to increased its solubility and decrease its sealing ability ${ }^{(18,46)}$.

\section{CONCLUSIONS}

Within the parameters of the current study it could be concluded that Total Fill and Bio MTA exhibits less solubility $\%$ and better sealing ability compared to the Pro root MTA. Based on improved sealing ability of both Total Fill and Bio MTA material, they could be considered as a good choice for the replacement of conventional MTA as root end filling materials

\section{REFERENCES}

1. Damas B, Wheater M, Bringas J, Hoen M. Cytotoxicity comparison of mineral trioxide aggregates and EndoSequence bioceramic root repair materials.J Endod. 2011;37:372-5

2. Roberts H, Toth J, Berzins D, Charlton D. Mineral trioxide aggregate material use in endodontic treatment: a review of the literature. Dent Mater. 2008; 24:149-64.

3. Torabinejad M, Higa R, McKendry D, Ford T. Dye leakage of four root end filling materials: effects of blood contamination.J Endod. 1994; 20:159-63.

4. Gagliani M, Taschieri S, Molinari R. Ultrasonic root-end preparation: influence of cutting angle on the apical seal.J Endod. 1998; 24:726-30.

5. Sauveur G, Boccara E, Colon P, Sobel M, Boucher Y. A photoelastimetric analysis of stress induced by root-end resection.J Endod. 1998; 24:740-3.

6. Min M, Brown C, Legan J, Kafrawy A. In vitro evaluation of effects of ultrasonic root-end preparation on resected root surfaces.J Endod. 1997; 23:624-8.

7. Gartner A, Dorn S. Advances in endodontic surgery. Dent Clin of North America. 1992; 36:357-78.

8. Costa AT, Konrath F, Dedavid B, Weber JB, de Oliveira MG. Marginal adaptation of root- endfilling materials: An in vitro study with teeth and replicas. J Contemp Dent Pract. 2009; 10:75-82.

9. Aqrabawi J. Sealing ability of amalgam, super EBA cement, and MTA when used as retrograde filling materials. Br Dent J. 2000; 188:266-8.

10. Vivan R, et al. Evaluation of the physical and chemical properties of two commercial and three experimental rootend filling materials. Oral Surg Oral Med Oral Pathol Oral Radiol Endod. 2010 110:250-6.

11. Grossman LI. Solubility of root canal cements. J Dent Res. 1978; 57:927.

12. Geneva: International Organization for Standardization; 2001. International Organization for Standardization. Specification for dental root canal sealing materials: ISO 6876.

13. Poggio C, Lombardini M, Alessandro C, Simonetta R. Solubility of root-end-filling materials: A comparative study. J Endod. 2007; 33:1094-7.

14. Torabinejad M, Hong CU, McDonald F, Pitt Ford TR. Physical and chemical properties of a new root-end filling material. J Endod. 1995; 21:349-53. 
15. Danesh G, Dammaschke T, Gerth HU, Zandbiglari T, Schäfer E. A comparative study of selected properties of Proroot mineral trioxide aggregate and two Portland cements. Int Endod J. 2006; 39:213-9.

16. Torabinejad M, Watson T, Ford T. Sealing ability of a mineral trioxide aggregate when used as a root end filling material.J Endod. 1993; 19:591-5.

17. Hirschberg S, Patel S, Patel L, Kadouri D, Hartwell G. Comparison of sealing ability of MTA and endosequence bioceramic root repair material: A bacterial leakage study. Quintessence Int. 2013; 44:157-62

18. Wang Z, bioceramic materials in endodontics. endod topics,2015,32:1,3-30.

19. Chong B, Pitt T, Kariyawasam S. Tissue response to potential root-end filling materials in inflected root canals. Int Endod J. 1997; 30:102-14.

20. Torabinejad M, Hong C, McDonald F, Ford T. Physical and chemical properties of a new root-end filling material.J Endod. 1995; 21:349-53.

21. ANSI/ADA. Revised American National Standard/ American Dental Association specification no. 30 for dental zinc oxide eugenol and zinc oxide non-eugenol cements 7.3. 2001 .

22. Raghavendra S, Jadhav G, Gathani K, Kotadia P. Bioceramics in endodontics - a review. J Istanb Univ Fac Dent, 2017; 51:128-37.

23. Villegas J, Yoshioka T, Kobayashi C, Suda H. Obturation of accessory canals after four different final irrigation regimes.J Endod. 2002; 28:534-6.

24. Shahravan A, Haghdoost A, Adl A, Rahimi H, Shadifar F. Effect of smear layer on sealing ability of canal obturation: a systematic review and meta-analysis.J Endod. 2007; 33:96-105.

25. Karlovic Z, Pezelj S, Miletic I, Jukic S, Grgurevic J,Anic I. Erbium: YAG laser versus ultrasonic in preparation of root-end cavities.J Endod. 2005; 31:821-3.

26. Ari $\mathrm{H}$, Yaşar E, Belli S. Effects of $\mathrm{NaOCl}$ on bond strengths of resin cements to root canal dentin.J Endod. 2003; 29:248-51.

27. Abedi H, Van B, Wilder P, Torabinejad M. Effects of ultrasonic root-end cavity preparation on the root apex. Oral Surg, Oral Med, Oral Pathol, Oral Radiol, and Endodod. 1995; 80:207-13.

28. Saeed R, Siavash S, Shahriar S, Ensiyeh M, Majid A, Hadi $\mathrm{M}$, etal: In vitro comparison of apical microleakage fol- lowing canal obturation with lateral and thermoplasticized gutta-percha compaction techniques .African J of Biotech .2010;9:8235-40.

29. Rosales J, Olmedo V, Vallecillo M, Lunadel J. Influence of cavity preparation technique (rotary vs. ultrasonic) on microleakage and marginal fit of six end-root filling materials. Med Oral Pathol Oral Cir Bucal. 2011; 16:185-9.

30. Kocak M, Kocak S, Aktuna S, Gorucu J, Yaman S. Sealing ability of retrofilling materials following various root-end cavity preparation techniques. Lasers Med Sci. 2011; 26:427-31.

31. Pornamazeh T, Yadegari Z, Ghasemi A, Sheykh A, Shojaeian S. In Vitro Cytotoxicity and Setting Time Assessment of Calcium-Enriched Mixture Cement, Retro Mineral Trioxide Aggregate and Mineral Trioxide Aggregate. Iran Endod J. 2017; 12:488-92.

32. Khandelwal A, Karthik J, Nadig R, Jain A. Sealing ability of mineral trioxide aggregate and Biodentine as the root end filling material, using two different retro preparation techniques-An in vitro study. Int J Cont Dent Med Rev. $2015 ; 18: 540-4$.

33. Hirschberg C, Patel N, Patel L, Kadouri D, Hartwell G. Comparison of sealing ability of MTA and EndoSequence Bioceramic Root Repair Material: a bacterial leakage study. Quintessence Int. 2013; 44: 157-62.

34. Storm B, Eichmiller F, Tordik P, Goodell G. Setting expansion of gray and white mineral trioxide aggregate and portland cement. J Endod 2008; 34:80-82. 20.

35. Camilleri J. Hydration mechanisms of mineral trioxide aggregate. Int Endod J 2007; 40:462470. 21.

36. Camilleri J. Characterization and chemical activity of Portland cement and two experimental cements with potential for use in dentistry. Int Endod J 2008; 41:791-9.

37. Lee Y, Lee B, Lin F, Yun Lin A, Lan W, Lin C. Effects of physiological environments on the hydration behavior of mineral trioxide aggregate. Biomaterials 2004; 25:787-93.

38. Hayashi M, Shimizu A, Ebisu S.MTA for obturation of mandibular central incisors with open apices: case report Endod .2004; 30:120-22.

39. Lide D, CRC Handbook of Chemistry and Physics, 1998, 79th ed. Abingdon, UK: CRC Press, Taylor \& Francis, pp. 1- 10

40. Hungaro D, Minotti P, Rodrigues C, Zapata O, Bramante C, Filho M, etal .Effect of different radiopacifying agents on the physicochemical properties of white Portland cement and white mineral trioxide aggregate. J Endod. 2012; 38:394-7. 
41. Camilleri J. The physical properties of accelerated Portland cement for endodontic use. Int Endod J. 2008; 41:151-7.

42. Camilleri J, Cutajar A, Mallia B. Hydration characteristics of zirconium oxide replaced Portland cement for use as a root-end filling material. Dent Materials, 2011; 27, $845-54$

43. Viapiana, R., Flumignan, D., Guerreiro, J., Camilleri, J., \& Tanomaru, M. Physicochemical and mechanical properties of zirconium oxide and niobium oxide modified Portland cement-based experimental endodontic sealers. Int Endod J, 2013; 47, 437-48.

44. Poggio C, Dagna A, Ceci M, Meravini M, Colombo M, Pietrocola G. Solubility and $\mathrm{pH}$ of bioceramic root canal sealers: A comparative study. J Clin Exp Dent. 2017; 9:1189-94.

45. Asgary S, Eghbal M, Parirokh M. Sealing ability of a novel endodontic cement as a root-end filling material. J Biomed Mater Res A., 2008; 87,706-9.
46. Shokouhinejad N, Nekoofar MH, Ashoftehyazdi K, Zahraee S, Khoshkhounejad M. Marginal adaptation of new bioceramic materials and mineral trioxide aggregate: a scanning electron microscopy study. Iran Endod J. 2014; 9:144-8.

47. Oliveira H, Alencar A, Figueiredo J, Guedes O, de Almeida D, Estrela C. Evaluation of Marginal Adaptation of Root-End Filling Materials Using Scanning Electron Microscopy. Iran Endod J. 2013; 8:182-6.

48. Shishir M ,Jeevani E, Jayaprakash T, Bolla N, Vemuri S, Sunil R, etal. Evaluation of sealing ability of MM-MTA, Endosequence, and biodentine as furcation repair materials: UV spectrophotometric analysis". J Conserv Dent. $2014 ; 17: 340-3$.

49. Nair U, Ghattas S, Saber M, Natera M, Walker C, Pileggi R. A comparative evaluation of the sealing ability of 2 root-end filling materials: an in vitro leakage study using Enterococcus faecalis. Oral Surg, Oral Med, Oral Pathol, Oral Radiol, and Endod, 2011; 112, 74-7. 